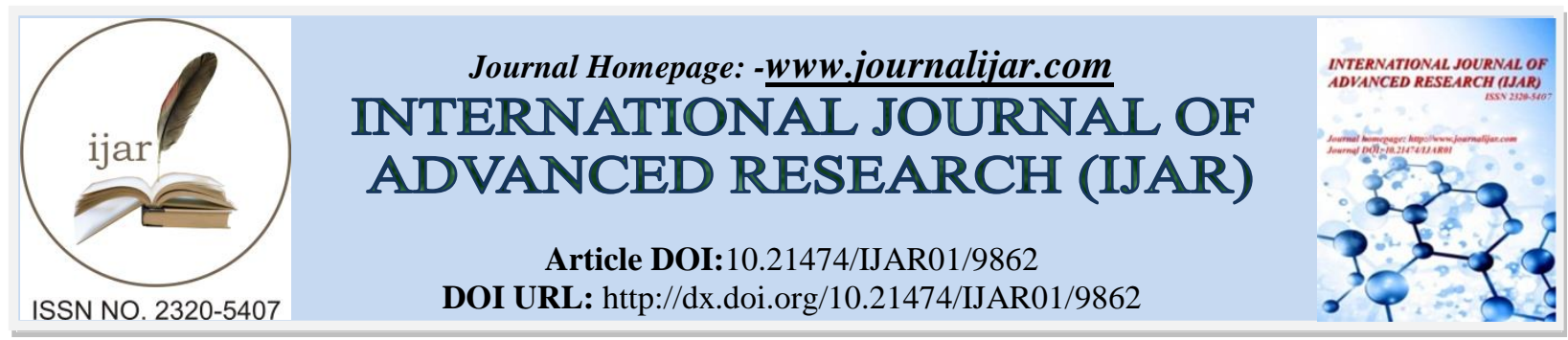

RESEARCH ARTICLE

\title{
A CASE OF HOMICIDAL CUT THROAT INJURY WITH CONCOMITANT TRANSECTION OF TRACHEA AND OESOPHAGUS.
}

\author{
Dr. Abhijit A. Whatkar ${ }^{1}$, Dr. Bhushan H. Mahamulkar ${ }^{2}$ and Dr. Krishna Narayan Tiwari ${ }^{3}$. \\ 1. Senior Consultant Surgeon, Department of General Surgery, Noble Hospital, Pune. \\ 2. Junior Resident, Department of General Surgery, Noble Hospital, Pune. \\ 3. Senior Resident, Department of General Surgery, Noble Hospital, Pune.
}

\section{Manuscript Info}

\section{Manuscript History}

Received: 08 August 2019

Final Accepted: 10 September 2019

Published: October 2019

Key words:-

Homicidal, cut- throat, airway, multidisciplinary.

\section{Abstract}

Homicidal cut-throat injuries are potentially life threatening because of the many vital structures that course through this area. Definite incidence of homicidal cut-throat injuries is unavailable as many are fatal before making it to a medical echelon. These patients need emergency and multispecialty care with multidisciplinary approach. Managing these cases at peripherally located sub-optimally equipped medical setups is a challenge in itself and despite being apparently stable and breathing spontaneously, these patients rapidly deteriorate. Expertise in managing airway is pivotal in securing a definitive airway in such cases thereby facilitating the wound exploration and surgical repair. We present a patient who was the victim of a homicidal cutthroat injury referred to us from a peripherally located medical setup.

Copy Right, IJAR, 2019,. All rights reserved.

\section{Introduction:-}

Cut throat injury is an incised injury in the neck that may be superficial or deep; and is usually caused by sharp objects [1]. The cause of the cut throat injury may be homicidal, suicidal or accidental [2]. Cut throat injuries are potentially life-threatening because many vital structures are present in such a small confined area. It can also result into profound morbidity due to prolonged hospitalization, high cost of health care service, loss of productivity and reduced quality of life [3].These patients need an emergency and multispecialty care, multidisciplinary approach is mandated to manage such cases [4]. No definite incidence of homicidal cut throat injuries is available as many are fatal before making it to a medical echelon. Penetrating injuries of the neck involve the larynx in approximately 5$15 \%$ of patients and chances of associated vascular or oesophageal injuries also being two folds as likely to have airway injuries [5]. Crico-tracheal junction by virtue of having thin connective tissues is a common site of tracheal transection [6]. We present a case report of a young male, a victim of homicidal cut-throat injury initially managed at a peripherally located medical setup; referred to us for further management leading to a good final outcome.

\section{Case report:}

A 28 year old young male was brought to our emergency department, with a history of cut throat injury about 3-4 hours back. There was an alleged history of homicide caused by a sharp weapon and the patient was referred from a peripheral centre for further management. The referral record indicated that he was intubated and ventilated; nasogastric tube was inserted; stabilized haemodynamically and transfused with packed cell volume. On examination, he was conscious but drowsy with pulse - 110/min and BP - 128/96 mmHg. Local examination revealed a linear cut throat injury with a horizontally lacerated wound over the anterior aspect of the neck extending 
from the right to left sternocleidomastoid at the level of thyrohyoid membrane. Complete transaction of trachea and oesophagus was present. Nasogastric tube and endotracheal tube were found in situ. There was no evidence of major vessel injury. (Fig.1) No bruises or any other lacerations were seen in relation to the said wound. After orthopaedic clearance for any suspected spinal trauma, an immediate exploration of the injury under general anesthesia was undertaken. On exploration of the wound, complete transection of trachea and oesophagus with wide separation of the ends, and cutting off the strap muscles was observed (Fig.1). No injury to great vessels or to any other adjoining structures in the neck was observed. Oesophagus was repaired over the nasogastric tube and an end to end anastomosis was done using absorbable sutures. Tracheal rings were approximated with the epiglottis in two layers using absorbable sutures. Strap muscles were approximated using absorbable sutures. A vacuum drain was placed subplatismally and wound was closed in layers (Fig.2).

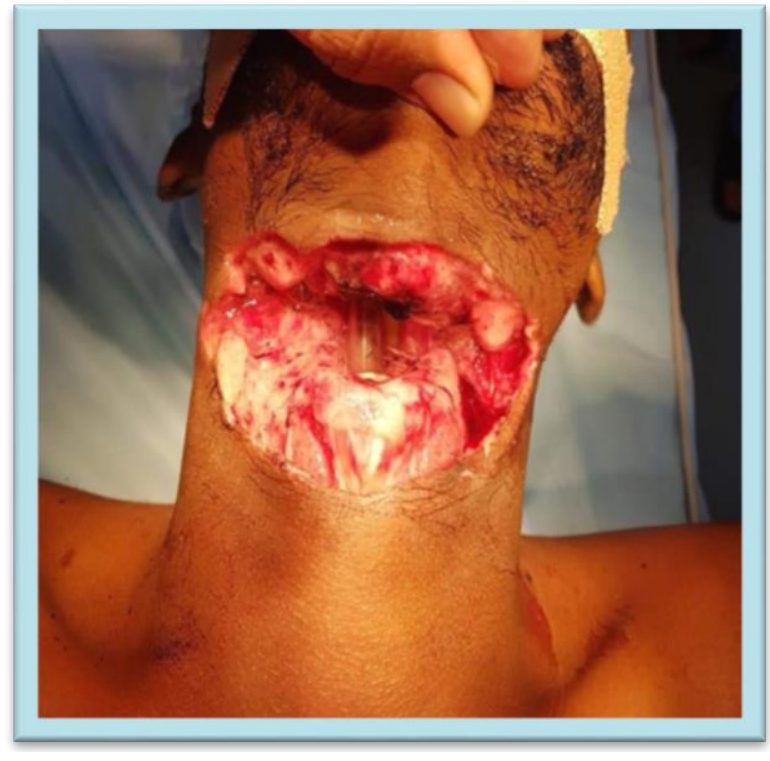

Fig. 1 - Cut throat injury over the neck at the level of thyrohyoid membrane.

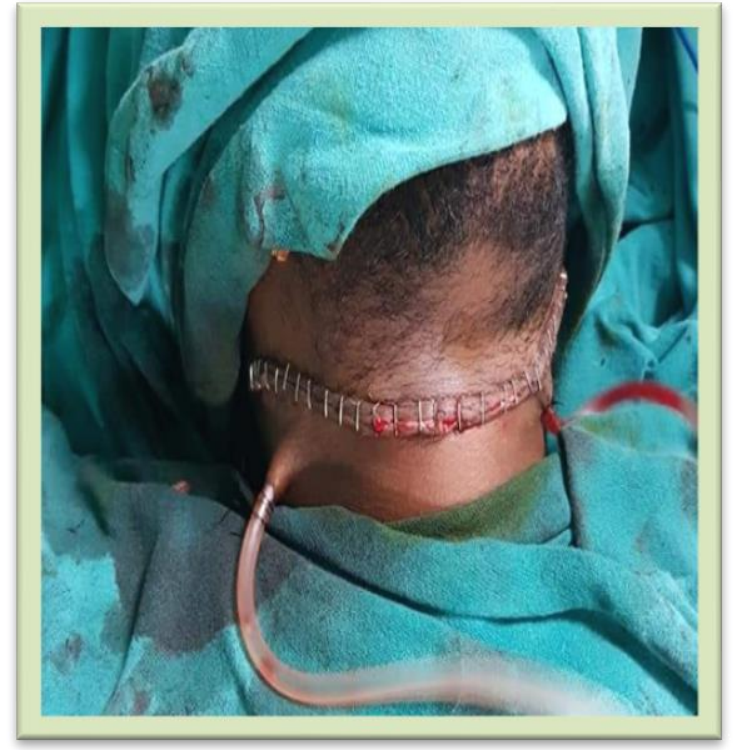

Fig.2 - Immediately post surgery

The patient was shifted to the ICU postoperatively. Patient was closely monitored post operatively and received I.V. antibiotics and parenteral nutrition. Nasogastric feeding was started on $5^{\text {th }}$ day post operatively. Ventilator weaning trial was given and endotracheal (ET) tube was removed. Post ET tube removal, the patient was comfortable; saturation was maintained (99\%); cough was absent; stridor was present.

A decision of elective tracheostomy was taken in view of progressively increasing stridor, cough, protection of proximal tracheal stitches and development of complications. Tracheostomy was done using a No. 8 portex tracheostomy tube. The patient was permitted to take sips of water orally from postoperative day 7. Oral intake was gradually increased as per tolerance and semi-solid diet was allowed after 2 weeks postoperatively. The patient had swallowing difficulties and cough initially which subsided with each passing day. However the patient still had difficulty with phonation. The patient was discharged after a long course of 26 days with tracheostomy tube in situ. A week after discharge, the portex tracheostomy was changed to a metallic one and the patient was advised to undertake speech therapy for vocal rehabilitation. The patient underwent regular follow up and speech therapy and had a very good outcome in terms of both breathing and speech with no untoward incident to report.

\section{Discussion:-}

Concomitant transection of airway and oesophagus in patient with cut throat injury is rare. Search of the published data reveals few cases of blunt trauma neck with airway and oesophageal transections. None of them has been the outcome of suicidal cut throat injury [7]. Oesophagus being posterior to trachea is rarely injured in homicidal or suicidal cut. Homicidal cut throats can be produced in two different ways; depending on whether they are produced from the back or the front [8].Of those two methods, cutting a person's throat from behind is the most common. The 
homicidal cut throat injuries inflicted from behind are usually longer. They usually start below the ear, run obliquely downward and medially, then straight across the midline of the neck, and end on the opposite side of the neck, lower than its point of origination [9].

Only a small subset of laryngotracheal injuries caused by homicidal cut throat is saved. Injury to vital structures including nerves, vessels, thyroid and oesophagus remains the main reason for death [10].

We thus describe our experience with a survivor of a homicidal cut throat injury with complete trachea- oesophageal transection. Some points in the early management of our patient are noteworthy in the discussion. Crico-tracheal separation can result in death. This patient survived primarily due to the prompt evacuation of the patient to the nearest district hospital, where the endotracheal intubation and nasogastric tube was inserted and airway was secured. The case thus highlights the importance of initial airway management in all such cases. Another factor which contributed to the survival of the patient was the timely referral to a tertiary care hospital and immediate exploration of the injury. This delineated the nature of cricotracheal and the concomitant oesophageal injury and helped in repairing it promptly. Patients with completely transected trachea can survive and sustain systemic saturation for several hours and are salvageable. These patients can even instantly desaturate and exsanguinate if distal trachea retracts in to mediastinum [6]. In an injured trachea, it is always preferable to maintain the patency and reduce the effort of breathing and avoid the blood entering the trachea by placing an advanced airway such as an endotracheal tube through the defect and utilize it subsequently for the surgical repair. Literatures have reported about the non-surgical management of tracheal injuries, but most of them suffer some residual airway or speech impairment [11]. In our patient, the trachea was surgically repaired, instead of waiting to heal spontaneously. Oesophagus was repaired using absorbable sutures and we did not observe any postoperative leak from our oesophageal anastomosis following removal of nasogastric tube. Early surgical management is also associated with significantly lower incidence of subglottic stenosis and improved outcomes with respect to airway and voice [1214].

Our experience reinforces the concept that if surgery is clearly indicated on clinical grounds, CT scan is unwarranted [15]. Moreover, critical time may be lost in procuring these investigations as patient is already in a precarious state. Thus, it is pertinent to note that in a deep incisional injury of neck, these investigations are not mandatory and surgical exploration is certainly the best diagnostic and therapeutic exercise undertaken in the best interest of patient care. Distal tracheostomy in the patients with tracheal repair is a disputed topic [16]. We did it in our case for safeguarding the proximal tracheal anastomosis and expected prolonged invasive ventilation.

\section{Conclusion:-}

Homicidal cut throat injuries are not uncommon, but literature about its incidence and survival rate is not available. Early decision and intervention to secure the airway, not only permits a controlled milieu for resuscitation but is also prudent to avoid any catastrophic airway compromise. Early presentation to the hospital, immediate and timely management by the intensivist, anaesthesiologist and surgeon offers a successful outcome. Stringent and appropriate measures by the government agencies for enforcement of law and order will reduce the burden of homicidal cut throat in near future $[17,18]$. Mans never ending greed towards materialistic necessities requires to be addressed in order to curb such incidences in which a precious life is jeopardized.

\section{References:-}

1. Duncan JAT. A case of severely cut throat injury. Br J Anaesth 1975;47:1327-1329.

2. Manilal A, Khorshed ABM, Talukder DC, Sarder RMA, Fakir AT, Hossain M. Cut throat injury: A review of 67 cases. Bangladesh J Otorhinilaryngol 2011;17:513.

3. Krug EG, Sharma GK, Lozano R. The global burden of injuries. Am J Publ Health 2000;90:523-526.

4. Herzog M, Hoppe F, Baier G, Dieler R (2005) Injuries of the head and neck in suicidal intention. Laryngorhinootologie 84: 176-181.

5. Rao BK, Singh VK, Ray S, Mehra M (2004) Airway management in trauma. Indian. J Crit Care Med 8: 98-105.

6. Cicala RS, Kudsk KA, Butts A, Nguyen H, Fabian TC (1991) Initial evaluation and management of upper airway injuries in trauma patients. J ClinAnesth 391-98.

7. A.E. O'Connor, J. Cooper, Case of the month: complete transection of the trachea and oesophagus in a 10 year old child: a difficult airway problem, Emerg. Med. J. 23 (2) (2006 Feb) 156-159.

8. Di Maio DJ. Di Maio VJM. Forensic pathology, 2nd ed. Florida, CRC Press LLC, 2001. 
9. Mize KD, Shackelford TK. Intimate partner homicide methods in heterosexual, gay, and lesbian relationships. Violence and Victims. 2008;23(1):98-114.

10. Grewal H, Rao PM, Mukerji S, Ivatury RR (1995) Management of penetrating laryngotracheal injuries. Head Neck 17: 494-502.

11. Glinjongol C, Pakdirat B (2005) Management of tracheobrochial injuries: A 10 year experience at Ratchaburi hospital. J Med Assoc Thai 88: 32-40.

12. D. A. Leopold, "Laryngeal trauma. A historical comparison of treatment methods," Archives of Otolaryngology, vol. 91, no. 2, pp.399-402, 1983.

13. G. S. Gussack and G. J. Jurkovich, "Treatment dilemmas in laryngotracheal trauma," Journal of Trauma, vol. 28, no. 10, pp.1439-1444, 1988.

14. D. J. McCrystal and C. Bond, "Cricotracheal separation: a review and a case with bilateral recovery of recurrent laryngeal nerve function," Journal of Laryngology and Otology, vol. 120,no. 6, pp. 497-501, 2006.

15. S. D. Schaefer, "The treatment of acute external laryngeal injuries. "State of the Art"," Archives of Otolaryngology, vol.117, no. 1, pp. 35-39, 1991.

16. Hermes C. Grillo, Reconstruction of the trachea. Experience in 100 consecutive cases, Thorax 28 (1973) 667.

17. Aich, M., Alam, K., Talukder, D.C., Sarder, R., Fakir, A.Y. and Hossain, M. (2011) Cut Throat Injury: Review of 67 Cases. Bangladesh Journal of Otorhinolaryngology, 17, 5-13.

18. Kundu, R.K., Adhikary, B. and Naskar, S. (2013) A Clinical Study of Management and Outcome of 60 Cut Throat Injuries. 